\title{
Understanding Kantian Understanding
}

Angela Breitenbach

Over the last decade or so philosophers have become increasingly dissatisfied with the dominant focus on the notion of knowledge in contemporary epistemology. Understanding, it has been suggested, is an important intellectual goal, often valuable over and above knowing the facts. But there is much disagreement over how exactly this suggestion is to be spelt out. Does understanding consist in a specific form of knowledge? ${ }^{1}$ Or is it a cognitive state intrinsically distinct from, and irreducible to, knowledge ? $^{2}$ And if the latter, how does understanding differ from knowledge?

In this paper, I sketch an answer to these questions which I attribute to Kant. By contrast with contemporary accounts, Kant's primary epistemological concern lies not with knowledge but with cognition and its intuitive and conceptual conditions. What contemporary epistemologists call 'understanding' is, for Kant, a type of cognition. Knowledge, by contrast, does not present a form of cognition and, hence, differs in important respects from understanding. This conclusion, however, does not imply a multiplicity of potentially conflicting cognitive goals. The important insight of Kant's account, I argue, is that the search for understanding is an indispensable means in the search for knowledge. ${ }^{3}$

\section{Understanding as faculty and achievement}

In the Critique of Pure Reason, Kant introduces the understanding (der Verstand) as one of "the higher cognitive faculties" ( $K r V, \mathrm{~A} 130 / \mathrm{B} 169)$, the faculty to judge or think. As a spontaneous rather than receptive capacity it is importantly distinct from sensibility. While sensibility receives indeterminate input directly, the understanding determines sensory input by means of concepts. Despite this difference, however, Kant famously argues that "it is just as necessary" for cognition

\footnotetext{
${ }^{1}$ E.g., P. Lipton, Inference to the Best Explanation, London: Routledge, 2004.

${ }^{2}$ E.g., L. Zagzebski, 'Recovering Understanding', in M. Steup (ed.), Knowledge, Truth and Duty, Oxford 2001, 235-251; C. Elgin, 'Understanding the Facts', Phil. Studies 132 (2007), 33-42; D. Pritchard, 'Knowledge and Understanding', in A. Fairweather (ed.), Virtue Epistemology Naturalized, Dordrecht: Synthese Library, 2014, 315-327.

${ }^{3}$ To avoid complication, I focus only on empirical knowledge and understanding.
} 
to make the mind's concepts sensible [sinnlich machen,] (i.e., to add an object to them in intuition) as it is to make its intuitions understandable [verständlich machen] (i.e., to bring them under concepts) (my italics, $K r V$, A51/B75).

The understanding, thus construed as a faculty of the human mind, has little in common with the notion of understanding discussed in contemporary epistemology. As the cited passage indicates, however, Kant construes understanding not only as the faculty of cognition (henceforth 'the understanding'), but also as the result of employing this faculty (henceforth simply 'understanding').This second notion of understanding as intellectual achievement recurs in the Jäsche Logic as the fifth item on Kant's list of seven "grades of cognition" ( $\log$, IX 64):

to understand something (intelligere), i.e., to cognize something through the understanding by means of concepts, or to conceive (Log, IX 65).

Understanding is a type of cognition by means of concepts, where cognition, the previous item on Kant's list, is characterized as "being acquainted with something with consciousness" ( $\log$, IX 65). The type of cognition which constitutes understanding requires both intuitions given in sensibility and conscious representation by means of concepts "that pertain to objects" ( $K r V$ A78-9/B104-5). If I understand that this ring is gold, for example, I conceive of the object in front of me under the concept 'gold' and thus pick it out and determine it by such marks as 'yellow', 'ductile' or 'does not rust'.

\section{Understanding, insight and comprehension}

Kant distinguishes understanding from more complex forms of representation that unify individual cognitions. In the Jäsche Logic, he differentiates understanding from the two highest forms of cognition, insight and comprehension:

\footnotetext{
${ }^{4}$ For recent discussions of Kant's notion of cognition - and of the progression of cognitions up to the fifth grade - see A. Chignell, 'Modal Motivations for Noumenal Ignorance: Knowledge, Cognition and Coherence', Kant-Studien 105 (2014), 573-597; E. Watkins and M. Willaschek, 'Kant on Knowledge and Cognition', Journal of the History of Philosophy (forthcoming); K. Schafer, 'Kant's conception of cognition and our Knowedge of Things-inThemselves' in N. Stang and K. Schafer (eds.), The Sensible and Intelligible Worlds (Oxford, forthcoming); and C. Tolley, 'Kant on the Place of Cognition in the Progression of our Representations' (ms).
} 
The sixth [grade of cognition]: to cognize something through reason, or to have insight [einsehen] into it (perspicere). With few things do we get this far, and our cognitions become fewer and fewer in number the more that we seek to perfect them as to content.

The seventh, finally: to comprehend [begreifen] something (comprehendere), i.e. to cognize something through reason or a priori to the degree that is sufficient for our purpose. For all our comprehension is only relative, i.e. sufficient for a certain purpose; we do not comprehend anything absolutely (Log, IX 64-5). ${ }^{5}$

The main difference is that insight and comprehension, but not understanding, present cognition through reason, the "faculty of inferring" ( $K r V, \mathrm{~A} 330 / \mathrm{B} 386)$, characterised by the search for the conditions of the objects of cognition. ${ }^{6}$ Insight and comprehension require not only that I recognise a given object under a concept, but also that I can infer its existence and specific features from general "principles" $(\mathrm{KrV}$, A299/B356). For example, in order to have insight into, and comprehend, what gold is, I need to understand not only what the properties of gold are but also "why it does not rust, why it is ductile, [and] heavier than others" (V-Lo/Blomberg, XXIV 135). ${ }^{7}$ Moving from understanding to insight and comprehension thus requires systematic cognition of an object under universal principles from which the properties of the object can be inferred a priori.

As we know from the Transcendental Dialectic, however, fully systematic cognition of the complete conditions of objects can never actually be achieved. All insight and comprehension are necessarily limited, falling short of ultimate explanations. The move from insight to comprehension can thus consist only in the move from incomplete insight to cognition that is sufficiently complete for a particular purpose. For example, if I were interested in comprehending why gold does not rust, it is sufficient for my purpose to learn that rust occurs as the result of a

\footnotetext{
${ }^{5}$ Cf. Refl, 2391; V-Lo/Blomberg, XXIV 133ff.; V-Lo/Pölitz, XXIV 539f.; V-Lo/Dohna, XXIV 730f.; V-Lo/Wiener, XXIV 846.

${ }^{6}$ There are good reasons to think that reason and its search for unity are already required to achieve understanding. Since I cannot go into these reasons here, for the purpose of this paper I take Kant's clear division between understanding and comprehension as the work of the understanding and of reason at face value.

${ }^{7}$ See also $V$-Lo/Wiener, XXIV 847.
} 
corrosion process, that this process involves the transfer of electrons from iron to oxygen in the presence of water, that gold is resistant to the same type of oxidation, and that it is resistant because its electronic configuration is too stable to give up electrons in normal environmental circumstances. Insight into these conditions of gold's resistance to corrosion would be sufficient relative to my interests, even though further questions could be asked, for instance, about the conditions of the electronic configuration of gold. Only insight that is relatively sufficient in this way constitutes 'comprehension'. ${ }^{8}$ As the highest, most ambitious, form of cognition attainable for us, Kant argues that it provides the basis for "science" ( $K r V$, A832/B860).

\section{Advancing understanding}

Seeing how different things we understand are systematically related and can be inferred from one another presents an accomplishment over and above the simple achievement of understanding. However, Kant also sometimes construes understanding in a third and stronger sense, for example, when he contends that "one always understands best what one can make oneself" (V-Lo/Dohna, XXIV 731). ${ }^{9}$

Kant does not suggest that making something oneself is a necessary condition for understanding. He argues rather that making something helps us gain understanding. In his Pedagogy Lectures he is more explicit: "The biggest aid to understanding something is to produce it" ( $P \ddot{d} d$, IX 477). Moreover, the reason why producing something is an aid to understanding is not simply that we practice concept application. It is, more specifically, that we learn to apply and infer from general principles and thereby come to grasp the laws and conditions that determine the thing's existence and specific nature. For example, in the Pedagogy Lectures, Kant is concerned with the use of the student's own reason in applying grammatical rules.

To make sense of Kant's link between understanding and making for oneself, I thus suggest we read Kant's claim as relying on a notion of advanced understanding, involving an intellectual achievement that results from the kind of unification Kant associates with insight and comprehension. The understanding resulting from such unification, moreover, is importantly continuous with basic forms of understanding. It consists in the more and more detailed conceptual representation, the deeper and

\footnotetext{
${ }^{8}$ See $V$-Lo/Dohna, XXIV 730f., and V-Lo/Wiener, XXIV 846.

${ }^{9}$ Kant makes similar claims in Päd, IX 477 and in a letter to J. S. Beck from $1^{\text {st }}$ July 1794 (XI $515)$.
} 
deeper understanding, of the objects given in sensibility. As Kant's use of "best" indicates, understanding comes in degrees, ranging from basic to more complex forms of cognition, systematically integrated under general principles to a higher and higher degree (V-Lo/Dohna, XXIV 731).

The suggested reading finds support in the way in which Kant introduces his list of the degrees of cognition in the Jäsche Logic. Kant there presents understanding, insight and comprehension as grades on a scale of cognition, progressing "in regard to [...] objective content" ( $\log$, IX 64). The more insight we gain into the connection between individual cognitions, the more we grasp about the general marks contained in our concepts and the specific marks falling under those concepts. And the deeper our grasp of the content and extension of our concepts, the more complete our understanding of the nature of the objects cognised by means of those concepts. Kant thus employs a gradual conception of understanding as consisting in the conceptual representation of an object given to the senses, a type of cognition that can be advanced, though never completed, by systematically unifying individual cognitions.

\section{Understanding and knowledge}

How, then, does understanding relate to knowledge? Kant's answer is far from straightforward. He takes up the topic of knowledge in the 'Canon of Pure Reason' and in the Lectures on Logic, but he remains silent on the relationship of knowledge to understanding. ${ }^{10}$ Despite such limited explicit engagement with the questions of this paper, however, recent commentators are agreed on two important insights they find in Kant. ${ }^{11}$ First, on Kant's account, knowledge is a type of representation that is importantly distinct from cognition. Kant characterises knowledge as a holding-to-betrue of a judgment, where this holding-to-be-true is both subjectively and objectively sufficient. Only knowledge, not cognition, thus requires assent to a judgment and justification of its truth. ${ }^{12}$ For example, I may understand my ring to be gold, and judge that it is made from a yellow, ductile metal that does not rust. And yet I may have no grounds for assenting to the truth of the cognition and withhold judgment when asked whether the gold-coloured material is genuine. I may withhold judgment,

\footnotetext{
${ }^{10} \mathrm{KrV}, \mathrm{A} 822 / \mathrm{B} 850$ and $\log$, IX 66.

${ }^{11}$ See the items in note 4.

${ }^{12}$ On the relation of cognition to truth, see $\mathrm{KrV}$, A58/B83.
} 
for instance, because upon consideration I deem my unaided identification of gold unreliable, and because I might discover that I am wearing a convincing fake.

Second, on Kant's account, the relationship between cognition and knowledge consists in the contributions cognition makes to the possibility of knowledge. Cognition can provide the judgments to which we assent in knowledge claims, and it can offer grounds for assenting to the propositions we take ourselves to know. My unaided detection of gold may not be especially reliable, for example, but my unaided identification of earrings certainly is. My observation that there is a pair of earrings in my jewellery box can thus serve as grounds for assenting to the claim that I own a pair, even if, by itself, such cognition is no adequate proof that the earrings I own are made of gold.

The concept of cognition on which commentators have focused is that of basic understanding. Recent discussions can therefore shed light on the relation between basic understanding and knowledge. Broadening the focus from basic to advanced understanding, however, raises additional questions. For even if individual cognitions can ground individual knowledge claims, it is unclear why systematically unified cognition should be a mark of science, something that for Kant - as for us - has an intrinsic connection with knowledge. ${ }^{13}$ But if science requires knowledge, why should we identify advanced understanding with "the scientific in cognition" $(\mathrm{KrV}$, A832/B860)? In other words, why should the goal of advancing understanding get us any closer to that of knowledge and truth?

Kant highlights the difference between advanced understanding and knowledge in the logic lectures. Like his list of the degrees of cognition that vary with respect to objective content, he presents opinion, belief and knowledge as ways of perfecting cognition. However, the two types of perfection occur along distinct dimensions. While the scale that culminates in understanding, insight and comprehension specifies how we can achieve deeper and deeper understanding, with more and more distinct objective content, the progress from opinion to belief and knowledge specifies differences in the degree of certainty with which we assent to the truth of cognition. The two types of perfection aimed at advanced understanding and knowledge are thus conceptually distinct; we may perfect cognition in one dimension without perfecting it in the other.

\footnotetext{
${ }^{13}$ See $M A N$, IV 468.
} 
Does this imply that the two types of perfection present two separate cognitive goals? Kant's answer, I suggest, is that although understanding does not require truth, the aim of advancing the former has an indispensable function in the search of the latter. In particular, advanced understanding is required for knowledge of the specific laws of nature and of their (possible) implications. ${ }^{14}$ As Kant argues in the Appendix to the Transcendental Dialectic, the search for higher-order principles from which lower-order marks can be inferred "always presupposes an idea, namely that of the form of the whole of cognition" ( $K r V$, A 645/B673). Although we can know a priori that all natural phenomena are governed by universal laws, only systematically unified cognition, or advanced understanding, can provide the objective grounds for assenting to the truth of judgments about empirical necessities. ${ }^{15}$

Kant thus concludes that "the systematic unity of the understanding's cognitions $[\ldots]$ is the touchstone of truth for its rules" $(\mathrm{KrV}, \mathrm{A} 647 / \mathrm{B} 675) .{ }^{16} \mathrm{By}$ analogy with a tool for assaying the purity of precious metals, Kant suggests that the systematic unification of individual cognitions, and hence the advancement of understanding, functions as a test - albeit a negative one - for the truth of empirical laws. Advancing understanding thus provides the means for seeking the objectively sufficient grounds for holding a judgment to be true or, simply, for knowledge.

\section{Concluding remarks}

The account suggested here of Kant's conception of understanding and its relation to knowledge remains at best a programmatic outline. It will require elaboration and justification. But if it can be shown, as Kant maintains, that unification is a test in the search for empirical truth, then advancing understanding will be our best guide in science. Although understanding and knowledge are distinct types of representation, they are thus indirectly related. The coherent unification of cognitions is not only a

\footnotetext{
${ }^{14}$ Watkins and Willaschek's (forthcoming) tentative proposal that "the grounds, or justification, required for knowledge could include the additional systematic and a priori requirements demanded for it to qualify as science properly so-called" holds, in my view, for the knowledge of laws and the knowledge gained by inference from general principles. Moreover, the suggestion would have to be extended to all knowledge claims if the inferences of reason and the idea of unity turn out to be central also for basic understanding; cf. note 6 . ${ }^{15}$ For a more detailed discussion of this, see my 'Kant on Causal Knowledge', in K. Allen und T. Stoneham (eds.), Causation and Modern Philosophy, London 2011, 201-219.

${ }^{16}$ See also $K r V$, A493/B521f. In a similar vein, Kant attributes the "consciousness of truth throughout" to perfect insight in the logic lectures (V-Lo/Dohna, XXIV 731). See also Refl. 2441, XVI 368.
} 
means of advancing understanding, but also a test of the truth of what we understand. Rather than presenting isolated goals, advancing Kantian understanding provides an indispensable means in the search for knowledge.

It is sometimes suggested that understanding is more demanding than knowledge. If we understand how rainbows come about we do not only know that they are the effect of sunlight, refracted and reflected through droplets of rain. We also have a deeper sense of how such knowledge fits in, more broadly, with the physics of optics and the physiology of colour vision. According to this suggestion, understanding a phenomenon is an intellectual achievement in addition to knowledge. According to Kant's conception, however, the initial plausibility of this suggestion is only partially defensible. On his account, knowledge of meteorological phenomena must ultimately be grounded in experience, and hence in sufficiently advanced understanding. On this conception, the example does not suggest that we can have knowledge without understanding. It shows rather that understanding may come in degrees, and that we can have a basic understanding of rainbows without possessing the advanced understanding of a trained physicist.

It is also sometimes argued that understanding is less demanding than knowledge. In the history of science, progression from one theory to another at times increased understanding even if neither theory was strictly speaking true. Newton's laws improved understanding of the motion of planets over and above that made possible by Kepler's laws, yet neither account got it all right. On the Kantian conception, we can account for such claims. We can argue that Newton's theory advanced understanding beyond Kepler's, insofar as Newton's account increased unification among cognitions. The fact that neither theory was strictly speaking true presents no obstacle to this claim. Furthermore, on Kant's account, the importance of this historical case concerns the insight that the goal of advancing understanding guides the search for knowledge. Even if, strictly speaking, neither Kepler's nor Newton's theory was able to ground knowledge, the continued attempt at advancing understanding provided the only available method of seeking a true account of planetary motion. 